Article

\title{
Toxic Effects of Urethane Dimethacrylate on Macrophages Through Caspase Activation, Mitochondrial Dysfunction, and Reactive Oxygen Species Generation
}

\author{
Chih-Yang Chang ${ }^{1}$, Chen-Yu Chiang ${ }^{2}$, Yun-Wei Chiang ${ }^{3}$, Min-Wei Lee ${ }^{4}$, Chien-Ying Lee ${ }^{5,6}$, \\ Hung-Yi Chen ${ }^{7}$, Hui-Wen Lin ${ }^{8,9, *}$ and Yu-Hsiang Kuan ${ }^{5,6, *(\mathbb{D})}$ \\ 1 Division of Pediatric Surgery, Department of Pediatrics, Ditmanson Medical Foundation Chia-Yi Christian \\ Hospital, 600 Chia-Yi City, Taiwan; 00880@cych.org.tw \\ 2 Department of Veterinary Medicine, National Chung-Hsing University, 402 Taichung, Taiwan; \\ online70222@gmail.com \\ 3 Department of Life Sciences, National Chung-Hsing University, 402 Taichung, Taiwan; \\ apple3793@gmail.com \\ 4 A Graduate Institute of Microbiology and Public Health, National Chung Hsing University, 402 Taichung, \\ Taiwan; cat852654@gmail.com \\ 5 Department of Pharmacology, School of Medicine, Chung Shan Medical University, 402 Taichung, Taiwan; \\ cshd015@csmu.edu.tw \\ 6 Department of Pharmacy, Chung Shan Medical University Hospital, 402 Taichung, Taiwan \\ 7 School of Pharmacy, China Medical University, 404 Taichung, Taiwan; hungyi@mail.cmu.edu.tw \\ 8 Department of Optometry, Asia University, 413 Taichung, Taiwan \\ 9 Genetics Center, Department of Medical Research, China Medical University Hospital, and School of \\ Chinese Medicine, China Medical University, 404 Taichung, Taiwan \\ * Correspondence: d9138001@asia.edu.tw (H.-W.L.); kuanyh@csmu.edu.tw (Y.-H.K.)
}

Received: 3 June 2020; Accepted: 18 June 2020; Published: 22 June 2020

check for updates

\begin{abstract}
Urethane dimethacrylate (UDMA) is a dimethacrylate-based resin monomer that can react with other related monomers and inorganic particles, causing hydrophobic polymerization through cross-linking upon light activation. UDMA polymers are commonly used for the reconstruction and reinforcement of teeth and bones. UDMA can become unbound and be released from light-cured polymer resins. Thus far, no evidence exists on the toxic effects of UDMA and its related working mechanisms for macrophages. Therefore, in the present study, we investigated the cytotoxicity, mode of cell death, DNA damage, caspase activities, mitochondrial dysfunction, and reactive oxygen species (ROS) generation in RAW264.7 macrophages treated with UDMA using the lactate dehydrogenase (LDH) assay kit, Annexin V-FITC and PI assays, micronucleus formation and comet assay, caspase fluorometric assay, JC-1 assay, and $2^{\prime}, 7^{\prime}$-dichlorofluorescin diacetate (DCFH-DA) assay, respectively. Our results show that UDMA induced cytotoxicity; apoptosis and necrosis; genotoxicity, which is also called DNA damage; increased caspase-3, -8 , and -9 activities; mitochondrial dysfunction; and intracellular ROS generation in a concentration-dependent manner in RAW264.7 macrophages. Thus, based on the observed inhibited concentration parallel trends, we concluded that UDMA induces toxic effects in macrophages. Furthermore, UDMA-induced intracellular ROS generation, cytotoxicity, and DNA damage were reduced by N-acetyl-L-cysteine.
\end{abstract}

Keywords: UDMA; macrophage; genotoxicity; apoptosis; ROS generation; caspase activation 


\section{Introduction}

Urethane dimethacrylate (UDMA) is a dimethacrylate-based resin monomer used in restorative dentistry and the repair of bone tissue [1]. UDMA and related monomers, including bisphenol A glycol dimethacrylate (BisGMA), triethylene glycol dimethacrylate (TEGDMA), and bisphenol A ethoxylated dimethacrylate (BisEMA), with their inorganic particles are activated by light to induce hydrophobic polymerization through cross-linking [2]. Such polymers are used for the reconstruction and reinforcement of teeth and bones. UDMA exists in an unbound state in light-cured polymers. Moreover, UDMA and its related dimethacrylate monomers can be released from the light-cured polymeric resins and can enter the peripheral tissues, oral cavity, and pulp [3]. Unbound UDMA or UDMA leakage would induce harmful reactions in the peripheral environment. UDMA is the main leached component from dental bonding agents or resin composites, causing impaired healing, inflammation, and necrosis in pulp tissue [4]. Toxic effects, including cytotoxicity, genotoxicity, and apoptosis, were induced by UDMA in human pulp cells and Chinese hamster ovary $(\mathrm{CHO})$ cells [5-7].

Macrophages, which play a critical role in the immune system, are ubiquitous in many peripheral tissues, including oral tissue. They serve as the first line of defense against invading microbial pathogens and unfamiliar chemicals. Pathogens and chemicals may cause overactivation of macrophages, resulting in an inflammatory response [8] and leading to pulpitis, periodontitis, and oral ulcers [9]. Based on the inflammatory reactions induced by dental bonding agents or resin composites in pulp tissue, we hypothesize that macrophages are affected by UDMA. Therefore, in the present study, we investigated the toxic effects of UDMA, such as DNA damage, cysteine-containing aspartate-specific protease (caspase) activities, and reactive oxygen species (ROS) generation, on a murine macrophage cell line, RAW264.7.

\section{Materials and Methods}

\subsection{Materials}

Dulbecco's Modified Eagle Medium (DMEM), fetal bovine serum (FBS), and other cell culture reagents were obtained from Thermo Fisher Scientific (Eugene, OR, USA). UDMA, cytochalasin B, dimethyl sulfoxide (DMSO), 5,5,6,6-tetrachloro-1,1,3,3-tetraethylbenzimidazolylcarbocyanine iodide (JC-1), phosphate buffered saline (PBS), and other chemical reagents were obtained from Sigma-Aldrich (St. Louis, MO, USA). Caspase-3, -8, -9 fluorometric assay kits were purchased from Alexis Biochemicals (Enzo Life Sciences, Plymouth Meeting, PA, USA).

\subsection{Cell Culture and Cell Treatment}

The murine macrophage cell line RAW264.7 (BCRC No.6001) was obtained from the Bioresource Collection and Research Centre of the Food Industry Research and Development Institute (Hsinchu, Taiwan). The cells were cultured in DMEM supplemented with $10 \% \mathrm{FBS}, 100 \mathrm{U} / \mathrm{mL}$ penicillin, and $100 \mu \mathrm{g} / \mathrm{mL}$ streptomycin in a humidified incubator at $37^{\circ} \mathrm{C}$ with $5 \% \mathrm{CO}_{2}$ and $95 \%$ air. Confluent cells were detached using $0.25 \%$ trypsin and $0.05 \%$ EDTA for $5 \mathrm{~min}$, and aliquots of the separated cells were subcultured at 1:4 splits every 3 days [10]. After incubation with or without N-acetyl-L-cysteine (NAC) at a concentration of $10 \mu \mathrm{M}$ for $30 \mathrm{~min}$, the cells were treated with UDMA at various concentrations of $0,1,10$, and $100 \mu \mathrm{M}$ for another $24 \mathrm{~h}$ for further experiments.

\subsection{Lactate dehydrogenase (LDH) Release Assay}

Cytotoxicity induced by UDMA in RAW264.7 cells was measured by the level of LDH released [11]. RAW264.7 cells were incubated with UDMA at various concentrations for $24 \mathrm{~h}$. The positive control group was incubated with a lysis solution to achieve the maximum level of LDH. The supernatant medium was incubated using the CytoTox 96 Non-radioactive Cytotoxicity Assay Kit (Promega, Madison, WI, USA) according to the manufacturer's instructions. Absorbance was detected at $490 \mathrm{~nm}$ 
using the Synergy HT multi-mode microplate reader (Biotek, Winooski, VT). The percentage of cytotoxicity was calculated as the ratio of LDH released from the cells treated with UDMA to that from the positive controls.

\subsection{Apoptosis and Necrosis Assay}

The Annexin V-FITC and PI assay kit (BioVision, San Jose, CA, USA) was used for the detection of apoptosis and necrosis as per the methodology used in a previous study. After treatment with UDMA at various concentrations for $24 \mathrm{~h}$, the cells were collected using ice-cold PBS [8]. The cells were incubated with Annexin V-FITC and PI in a binding buffer solution at $37^{\circ} \mathrm{C}$ in the dark. The samples were acquired and analyzed on the BD Accuri 66 flow cytometer using C6 software (BD Biosciences, San Jose, CA, USA). Percentages of cells in the stages of living, early apoptosis, late apoptosis, and necrosis were presented as annexin $\mathrm{V}-/ \mathrm{PI}-$, annexin $\mathrm{V}+/ \mathrm{PI}-$, annexin $\mathrm{V}+/ \mathrm{PI}+$, and annexin $\mathrm{V}-/ \mathrm{PI}+$, respectively.

\subsection{Micronucleus (MN) Formation Assay}

We used the micronucleus ( $\mathrm{MN}$ ) formation assay to assess the genotoxic effects (i.e., DNA damage) caused by UDMA, as previously described [12]. Briefly, the cells were treated with UDMA at various concentrations, $3 \mathrm{mg} / \mathrm{mL}$ cytochalasin B, and $0.17 \mu \mathrm{g} / \mathrm{mL}$ mitomycin $\mathrm{C}$ for $24 \mathrm{~h}$. Later, the cells were washed, resuspended in $75 \mathrm{mM} \mathrm{KCl}$, and then fixed in a mixture of methanol/acetic acid. They were stained using 3\% Giemsa solution. MN was analyzed microscopically in 1000 binucleated cells per concentration.

\subsection{Single-Cell Gel Electrophoresis (Comet) Assay}

To assess the DNA damage caused by UDMA, the comet assay was used, as outlined in a previous study [12]. After treatment, the cells were mixed with low melting agarose and mounted on microscope slides precoated with normal melting agarose and then covered using a coverslip on ice. After the coverslip was removed, the microscope slides were immediately submerged in a lysis solution containing $2.5 \mathrm{M} \mathrm{NaCl}, 100 \mathrm{mM}$ ethylenediaminetetraacetic acid (EDTA), $10 \mathrm{mM}$ Tris $\mathrm{pH} \mathrm{10,1 \%} \mathrm{Triton}$ $\mathrm{X}-100,200 \mathrm{mM} \mathrm{NaOH}, 34.1 \mathrm{mM} \mathrm{N}$-Lauroyl-Sarcosine, and $10 \%$ DMSO at $4{ }^{\circ} \mathrm{C}$ for $1 \mathrm{~h}$ in the dark. They were then washed and placed in a horizontal electrophoresis tank filled with electrophoresis buffer for $40 \mathrm{~min}$ at $4{ }^{\circ} \mathrm{C}$ for DNA unwinding and denaturation. The microscope slides were then incubated using a neutralization buffer $(0.4 \mathrm{M}$ Tris- $\mathrm{HCl}, \mathrm{pH} 7.5)$ and stained using ethidium bromide. The results were analyzed using the Comet v.5.5 system (Kinetic Imaging Ltd., Liverpool, UK). To quantify DNA damage, we evaluated the following comet parameters: percentage of DNA in the tail (\%DNA in tail; relative fluorescence intensity of tail) and tail length (distance from center of the head to the end of the tail).

\subsection{Assays to Measure Caspase- $3,-8$, and -9 Activities}

To assess the activation of caspase- $3,-8$, and -9 induced by UDMA, we used a previously described method [12]. After UDMA treatment, the level of proteins extracted from cells using a lysis buffer for $1 \mathrm{~h}$ at $4{ }^{\circ} \mathrm{C}$ was measured using the Bradford assay. Equal amounts of lysate protein were incubated with DEVD-AFC, IETD-AFC, and LEHD-AFC, which are fluorogenic substrates of caspase-3, -8 , and -9 , respectively. After a $2-\mathrm{h}$ incubation at $37^{\circ} \mathrm{C}$, the fluorescence intensity was detected using the microplate reader at excitation and emission wavelengths of 400 and $505 \mathrm{~nm}$.

\subsection{Mitochondrial Membrane Potential Assay}

To assess mitochondrial disruption, the mitochondrial membrane potential (MMP) was detected using JC-1, as described in previous research [10]. The cells were harvested after treatment, and they were incubated with $10 \mathrm{mg} / \mathrm{mL} \mathrm{JC}-1$ for $30 \mathrm{~min}$ at $37^{\circ} \mathrm{C}$ in the dark. Intracellular JC-1 fluorescence was acquired and analyzed on the BD Accuri $\mathrm{C} 6$ flow cytometer using $\mathrm{C} 6$ software. 


\subsection{Measurement of Intracellular ROS Level}

The level of intracellular ROS induced by UDMA was detected using $2^{\prime}, 7^{\prime}$-dichlorofluorescin diacetate (DCFH-DA), as described in previous research [12]. The cells were harvested after treatment, and the cells were incubated with $5 \mu \mathrm{M}$ DCFH-DA for $30 \mathrm{~min}$ at $37^{\circ} \mathrm{C}$ in the dark. Intracellular DCF fluorescence was assayed using the microplate reader (Biotek, Winooski, VT, USA) at excitation and emission wavelengths of 488 and $525 \mathrm{~nm}$, respectively.

\subsection{Statistical Analysis}

All experiments were performed in triplicate, and the results were analyzed using SPSS software (IBM, New York, NY, USA). The results are expressed as mean \pm standard deviation (SD). The significance of differences was calculated using one-way ANOVA, followed by the Bonferroni's test for multigroup comparison. A $P$ value of less than 0.05 was considered statistically significant.

\section{Results}

\subsection{Effects of UDMA on Cytotoxicity of RAW264.7 Cells}

To determine the cytotoxic effect induced by UDMA in macrophages, the RAW264.7 cells were incubated in UDMA at the indicated concentration for $24 \mathrm{~h}$. The cytotoxicity of RAW264.7 cells treated with UDMA at various concentrations of $0,1,10$, and $100 \mu \mathrm{M}$ for $24 \mathrm{~h}$ was measured using the LDH release assay (Figure 1). UDMA induced cytotoxicity in a concentration-dependent manner. Treatment with UDMA at $10 \mu \mathrm{M}$ induced significant cytotoxicity $(P<0.05)$ in RAW264.7 cells.

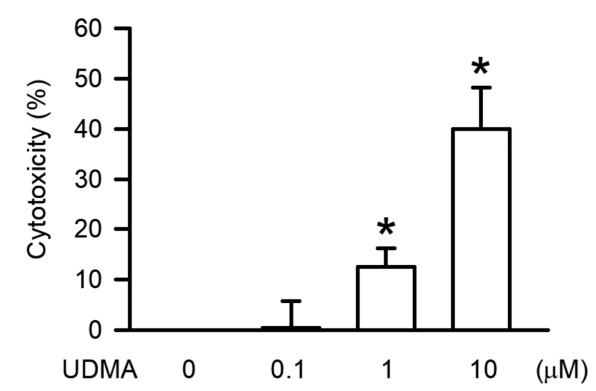

Figure 1. Urethane dimethacrylate (UDMA) induced cytotoxicity in RAW264.7 macrophages. The cells were incubated with UDMA at concentrations of $0,1,10$, and $100 \mu \mathrm{M}$ for $24 \mathrm{~h}$ at $37^{\circ} \mathrm{C}$. Cytotoxicity was measured using the LDH assay. Data are expressed as mean $\pm \mathrm{SD}(\mathrm{n}=5)$. ${ }^{*} P<0.05$ is considered significant compared with the control group.

\subsection{Effects of UDMA on Necrosis and Apoptosis of RAW264.7 Cells}

To study the role of apoptosis and necrosis, we studied the level of apoptosis and necrosis induced by UDMA in RW264.7 cells. As shown in Figure 2A, apoptosis and necrosis of RAW264.7 cells caused by UDMA were assessed using the annexin V-FITC and PI assay kit and a flow cytometer. After 24-h treatment with UDMA at concentrations of 10 and $100 \mu \mathrm{M}$, the cells in early apoptosis significantly increased $(P<0.05)$, from $5.56 \%$ to $12.43 \%-26.73 \%$, quantitatively. The cells in late apoptosis and necrosis also significantly increased $(P<0.05)$ after treatment with $100 \mu \mathrm{M}$ of UDMA, from $0.17 \%$ to $5.47 \%$ and $0.2-2.3 \%$, respectively (Figure $2 \mathrm{~B}$ ). These results indicate that UDMA induced early apoptosis at low concentrations and late apoptosis and necrosis at high concentrations. 
(A)
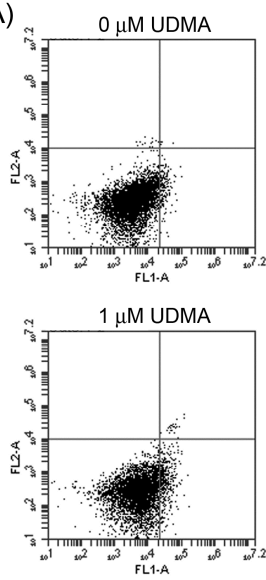
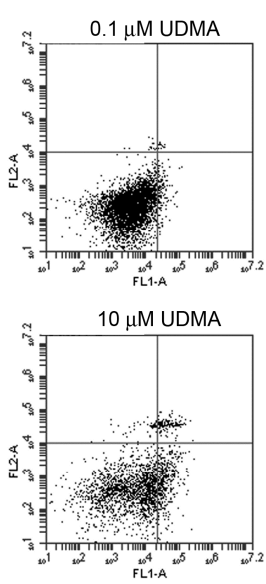

(B)

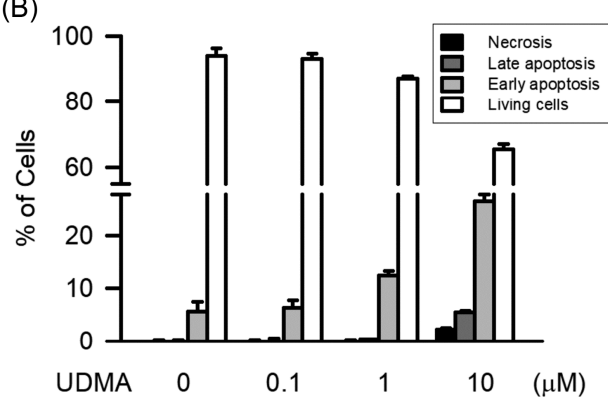

Figure 2. UDMA induced apoptosis and necrosis in RAW264.7 macrophages. The portion of apoptosis and necrosis was measured by Annexin V-FITC and PI assays using flowcytometry. (A) Cells were incubated with UDMA at concentrations of $0,1,10$, and $100 \mu \mathrm{M}$ for $24 \mathrm{~h}$ at $37{ }^{\circ} \mathrm{C}$. The upper left quadrant (Annexin $\mathrm{V}-/+$ ) is representative of necrosis; the upper right and lower right quadrants (Annexin $\mathrm{V}+/ \mathrm{PI}+$ and Annexin $\mathrm{V}+$ /PI-) are representatives of apoptosis; and the lower left quadrant (Annexin V-/PI-) is representative of living cells. (B) Quantitatively, the percentage of necrotic cells, viable cells, and apoptotic cells were calculated and analyzed. Data are expressed as mean \pm SD $(n=5)$. $* P<0.05$ is considered significant compared with the control group.

\subsection{Effects of UDMA on MN Formation in RAW264.7 Cells}

Genotoxicity plays a major role in the regulation of cytotoxicity via apoptosis. As shown in Figure 3, UDMA-induced genotoxic effects were measured using the MN assay. Our results show that UDMA induced MN formation significantly in a concentration-dependent manner, with significant effects beginning at a concentration of $10 \mu \mathrm{M}(P<0.05)$.

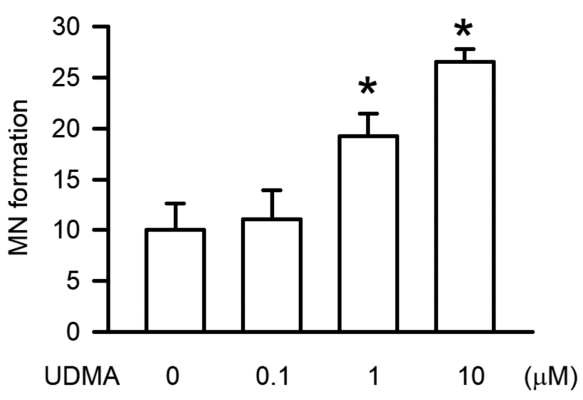

Figure 3. UDMA induced micronucleus (MN) formation in RAW264.7 macrophages. Data are expressed as mean $\pm \mathrm{SD}(\mathrm{n}=5) .{ }^{*} P<0.05$ is considered significant compared with the control group.

\subsection{Effects of UDMA on DNA Damage in RAW264.7 Cells}

DNA damage is the most important of the key features in the genotoxicity. As shown in Figure 4, UDMA-induced DNA damage was detected using the comet assay. Our results show that compared with controls, the tail length (Figure 4B) and \%DNA in the tail (Figure 4C) significantly increased in a concentration-dependent manner, with significant effects beginning at a concentration of $10 \mu \mathrm{M}$ $(P<0.05)$ 
(A)

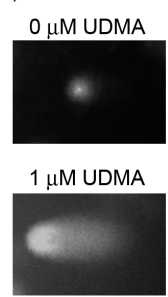

(C)

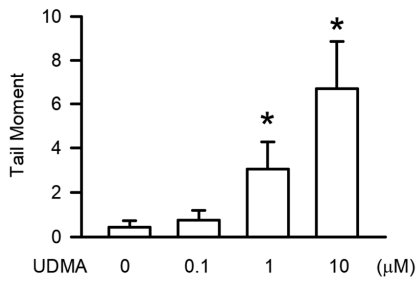

(B)

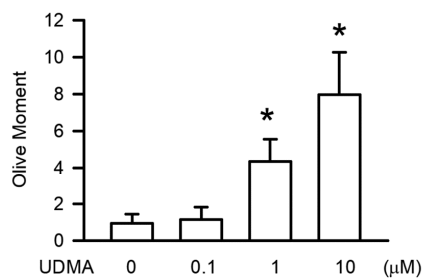

(D)

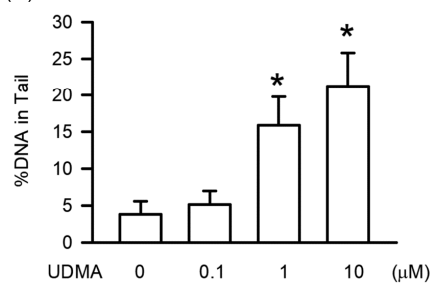

Figure 4. UDMA-induced DNA damage measured using the comet assay in RAW264.7 macrophages. (A) Gel electrophoresis of UDMA-treated RAW264.7 cells at concentrations of 0, 1, 10, $100 \mu \mathrm{M}$. (B) and (C) are quantifications of tail moment and (D) \%DNA in tail, respectively. Results are expressed as mean \pm SD. ${ }^{*} P<0.05$ is considered significant compared with the control group.

\subsection{Effects of UDMA on Caspase-3, -8, and -9 Activities in RAW264.7 Cells}

Caspase-3, caspase-8, and caspase-9 play important roles in apoptosis and DNA damage in cells. We measured caspase- $3,-8$, and -9 activities induced by UDMA using caspase fluorometric assay kits. After RAW264.7 cells were treated with UDMA, we observed that caspase-3, -8 , and -9 activities were induced by UDMA in a concentration-dependent manner, with significant effects beginning at a concentration of $10 \mu \mathrm{M}(P<0.05$, Figure 5$)$.

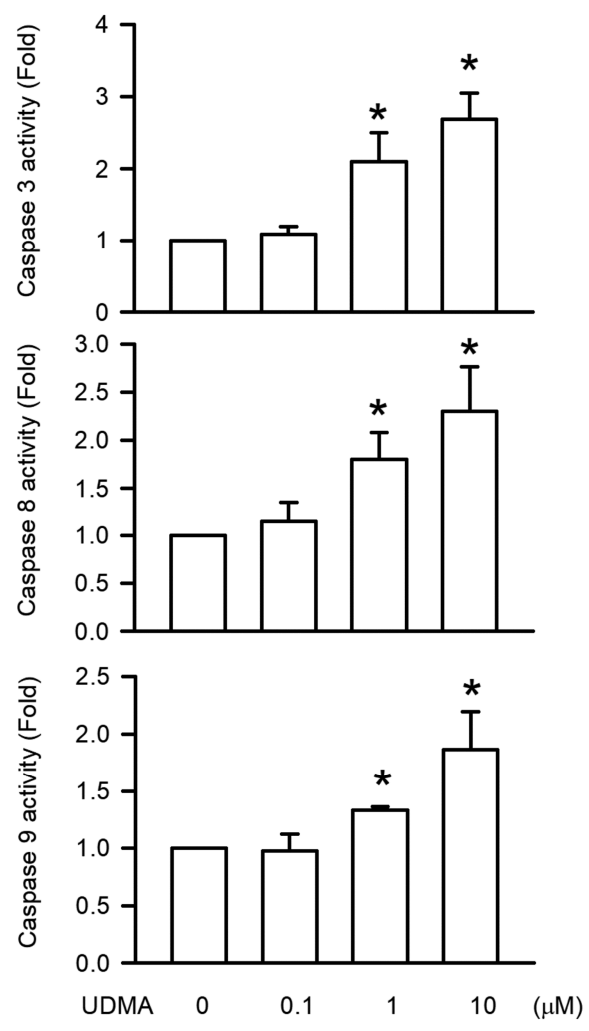

Figure 5. UDMA-induced caspase-3, -8 , and -9 activation in RAW264.7 macrophages. Data are expressed as mean $\pm \mathrm{SD}(n=5) .{ }^{*} P<0.05$ is considered significant compared with the control group. 


\subsection{Effects of UDMA on Mitochondrial Dysfunction in RAW264.7 Cells}

Mitochondrial dysfunction is the critical hallmark of apoptosis through caspase activation. As shown in Figure 6, UDMA-induced mitochondrial dysfunction was detected using a fluorescence-based mitochondria-specific voltage-dependent dye, JC-1. As shown in Figure 6A, the green fluorescence of JC1, indicating mitochondrial integrity, was induced by UDMA. Thus, our results showed that UDMA induced mitochondrial dysfunction in a concentration-dependent manner, with significant effects beginning at a concentration of $10 \mu \mathrm{M}(P<0.05$, Figure $6 \mathrm{~B})$.
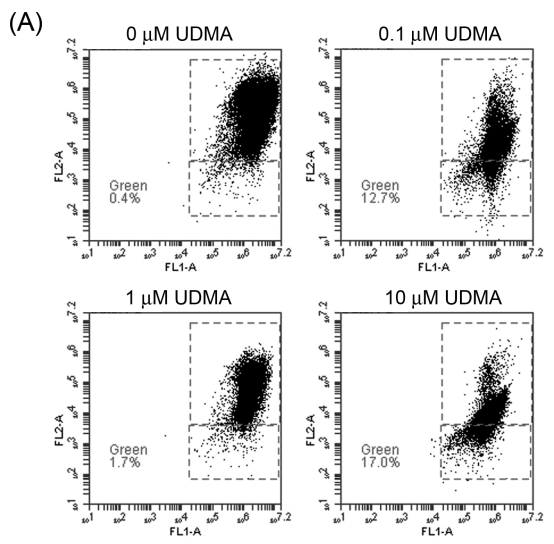

(B)

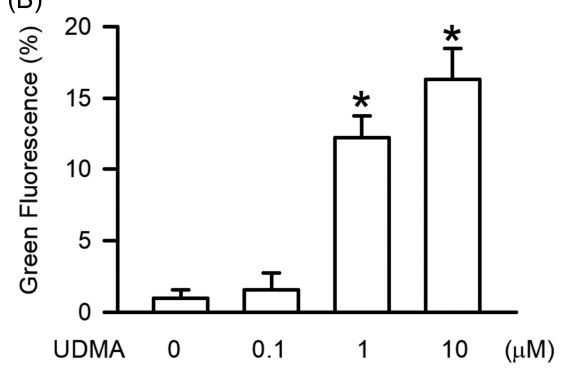

Figure 6. UDMA induced mitochondrial dysfunction in RAW264.7 macrophages. (A) Cells were incubated with UDMA at concentrations of $0,1,10$, and $100 \mu \mathrm{M}$ for $24 \mathrm{~h}$ at $37^{\circ} \mathrm{C}$. The portion of mitochondria dysfunction was measured using the JC1 assay. (B) Quantitatively, the percentage of cells with mitochondrial dysfunction were calculated and analyzed. Data are expressed as mean \pm SD $(\mathrm{n}=5) .{ }^{*} P<0.05$ is considered significant compared with control group.

\subsection{Effects of UDMA on Intracellular ROS Generation in RAW264.7 Cells}

ROS play a major role in genotoxicity and apoptosis. ROS generation in RAW264.7 cells after treatment with UDMA at the indicated concentrations for $24 \mathrm{~h}$ was detected using DCFH-DA. As shown in Figure 7, ROS generation was induced by UDMA in a concentration-dependent manner, with a significant increase in the level of ROS observed at a concentration of $10 \mu \mathrm{M}(P<0.05)$.

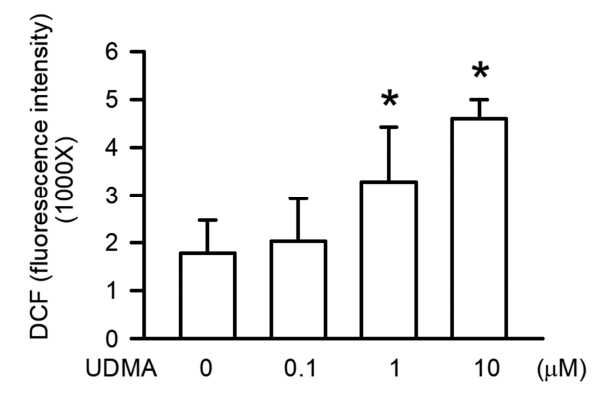

Figure 7. UDMA induced intracellular ROS generation in RAW264.7 macrophages. Data are expressed as mean $\pm \mathrm{SD}(\mathrm{n}=5) .{ }^{*} P<0.05$ is considered significant compared with control group. 
3.8. Effects of NAC on UDMA-Induced Intracellular ROS Generation, Mitochondrial Dysfunction, and Cytotoxicity in RAW264.7 Cells

NAC is employed as a cell-permeable ROS scavenger. RAW264.7 cells were pretreated with NAC to evaluate its effects on intracellular ROS generation, cytotoxicity, and mitochondrial dysfunction induced by UDMA. Our results showed that NAC significantly inhibited all three UDMA-induced effects $(P<0.05$, Figure 8$)$.
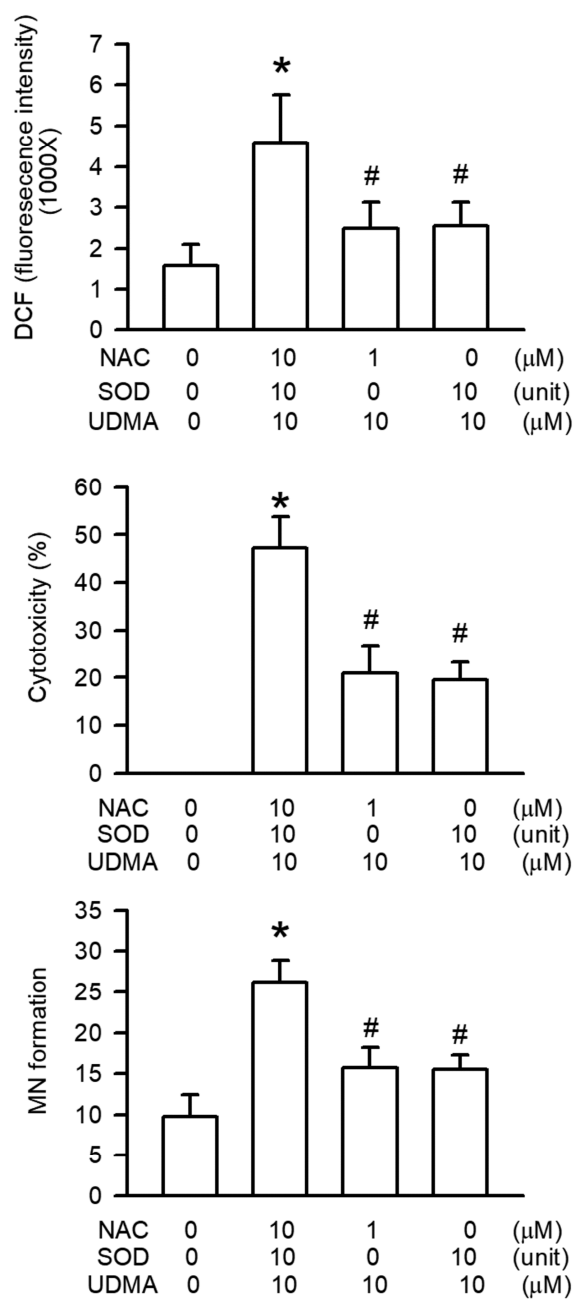

Figure 8. UDMA induced intracellular ROS generation in RAW264.7 macrophages. Data are expressed as mean $\pm \mathrm{SD}(\mathrm{n}=5)$. ${ }^{*} P<0.05$ is considered significant compared with control group.

\section{Discussion}

Monomers, including BisGMA, TEGDMA, bisphenol A (BPA), and UDMA, are leached from light-cured dimethacrylate dental resins into an aqueous environment at nanomolar ranges [13-15]. Our previous studies proposed that cytotoxicity may be induced by BisGMA, TEGDMA, and BPA in macrophages $[16,17]$. Considerable evidence has shown that cytotoxicity, DNA damage, and apoptosis are induced by UDMA at $1 \mathrm{mM}$ for $1 \mathrm{~h}$ in CHO cells [5]. After human dental pulp cells are incubated with UDMA at 0.05 to $0.35 \mathrm{mM}$ for $24 \mathrm{~h}$ or 0.1 and $0.3 \mathrm{mM}$ for $48 \mathrm{~h}$, there is a significant reduction in survival rate [6,7]. Human gingival fibroblasts treated with UDMA at $0.1 \mathrm{mM}$ for $24 \mathrm{~h}$ also demonstrated a reduction in survival rate [18]. UDMA at the concentration of 0.8 and $1 \mathrm{mM}$ for $24 \mathrm{~h}$ induces cytotoxicity in human lymphocytes [19]. However, UDMA-induced cytotoxicity in macrophages has not been demonstrated. Therefore, we investigated this topic, and our findings demonstrate that treatment with $10 \mu \mathrm{M}$ UDMA for $24 \mathrm{~h}$ induced significant cytotoxicity in RAW264.7 macrophages. These results are 
similar to those of a previous study, where peripheral blood mononuclear cell viability was reduced by $50 \%-93 \%$ upon treatment with UDMA at concentrations of 50-200 $\mu \mathrm{M}$ for $20 \mathrm{~h}$ [20]. These findings indicate that UDMA can induce cytotoxicity in human macrophages.

Apoptosis and necrosis are the two major processes of cell death [21-23]. Previous studies have implicated UDMA-induced apoptosis in human lymphocytes and CHO cells at $1 \mathrm{mM}$ for $6 \mathrm{~h}[5,19]$. UDMA induced a higher incidence of necrosis than apoptosis in human gingival fibroblasts [18]. After human dental pulp cells were incubated with UDMA at $0.35 \mathrm{mM}$ for $24 \mathrm{~h}$, a significant induction of apoptosis was observed [7]. Our study demonstrated that significant early apoptosis and late apoptosis and necrosis of macrophages are induced by UDMA at concentrations of 10 and $100 \mu \mathrm{M}$, respectively. Our results also suggest that the higher the concentration of UDMA, the more severe the cell damage (ranging from apoptosis to necrosis) in RAW264.7 macrophages. A previous study showed, using the comet assay, that UDMA dose-dependently induces cytotoxicity and apoptosis in lymphocytes through DNA damage $[5,19]$. In the present study, the comet and MN assays revealed DNA damage induced by UDMA, indicating that UDMA induced apoptosis in RAW264.7 macrophages through DNA damage.

The caspases, a family of intracellular cysteine proteases, serve as initiators and executioners in DNA damage and genotoxicity, resulting in apoptosis [24,25]. Caspase-3, the most crucial executioner caspase, promotes DNA damage and is activated by intrinsic and extrinsic pathways initiated by caspase- 9 and -8 , respectively $[24,26]$. We demonstrated increased activities of caspase- $3,-8$, and -9 induced by UDMA in a concentration-dependent manner in RAW264.7 macrophages, which is similar to the finding of UDMA-induced DNA damage and apoptosis. These results imply that apoptosis of macrophages is induced by UDMA through caspase-induced DNA damage.

Mitochondria play critical roles in cellular metabolism, homeostasis, and stress responses by generating ATP for energy and regulating cell death [27]. Mitochondrial dysfunction is usually caused by depolarization and is the early hallmark of toxicity mediated through caspase-induced apoptosis [28]. Our study provides convincing evidence indicating that UDMA dose-dependently caused caspase-induced apoptosis of RAW264.7 cells through mitochondrial dysfunction.

Intracellular ROS generation is a critical feature of mitochondrial dysfunction [29]. A previous study suggested that intracellular ROS generation is induced by UDMA in a concentration-dependent manner [30], and that the precursor of GSH and ROS scavenger, NAC, can prevent ROS generation and cytotoxicity in $\mathrm{CHO}$ cells [30]. In the current study, we observed that intracellular ROS generation was induced by UDMA in a concentration-dependent manner in RAW264.7 macrophages, which is similar to the precipitation of UDMA-induced mitochondrial dysfunction. These results thus suggest that mitochondrial dysfunction caused by UDMA occurs through intracellular ROS generation. Moreover, we discovered that NAC reduced UDMA-induced intracellular ROS generation, cytotoxicity, and genotoxicity in RAW264.7 macrophages. Based on these results, we suggest that UDMA-induced intracellular ROS generation from mitochondrial dysfunction resulted in toxic effects on macrophages, including genotoxicity, apoptosis, and cytotoxicity.

In conclusion, UDMA induced cytotoxicity of RAW264.7 macrophages in a concentration-dependent manner, which is associated with early apoptosis at low concentrations in contrast to late apoptosis and necrosis at high concentrations. The mechanisms involved are as follows: (1) DNA damage; (2) activation of caspase-3, -8, and -9; (3) mitochondrial dysfunction; and (4) generation of intracellular ROS. These results suggest that UDMA is a toxic reagent in macrophages. At present, we have enough evidence to support the hypothesis, which is that macrophages are injured by UDMA, which is released from restorative dental composites, and contributes to cytotoxicity and apoptosis via DNA damage, caspases activation, mitochondrial dysfunction, and ROS generation. These findings can be used in the future to develop the new treatment strategies for immune dysfunction related to macrophage damage caused by UDMA.

Author Contributions: Conceptualization, C.-Y.C. (Chih-Yang Chang), Y.-H.K., and H.-W. L.; methodology, C.-Y.C. (Chih-Yang Chang), C.-Y.C. (Chen-Yu Chiang), Y.-W.C., M.-W.L., H.-Y.C.; software, C.-Y.C. (Chih-Yang Chang), 
C.-Y.C. (Chen-Yu Chiang), Y.-W.C., H.-W.L.; validation, Y.-W.C., M.-W.L., H.-Y.C., and C.-Y.L.; formal analysis, Y.-W.C., M.-W.L., C.-Y.L., and H.-W.L.; investigation, C.-Y.C. (Chih-Yang Chang), H.-Y.C.,Y.-H.K., and H.-W.L.; resources, C.-Y.C. (Chih-Yang Chang), Y.-H.K., and H.-W. L.; data curation, Y.-W.C., M.-W.L., H.-Y.C., C.-Y.L., and H.-W.L.; writing - original draft preparation, C.-Y.C. (Chih-Yang Chang), C.-Y.C. (Chen-Yu Chiang), Y.-H.K., and H.-W.L.; writing-review and editing, C.-Y.C. (Chih-Yang Chang), Y.-H.K., and H.-W.L.; visualization, C.-Y.C. (Chih-Yang Chang), C.-Y.C. (Chen-Yu Chiang).; supervision, C.-Y.C. (Chih-Yang Chang), Y.-H.K., and H.-W.L.; project administration, Y.-H.K.; funding acquisition, C.-Y.C. (Chih-Yang Chang), Y.-H.K., and H.-W.L. All authors have read and agreed to the published version of the manuscript.

Funding: The authors would like to thank the Ministry of Science and Technology of the Republic of China, Taiwan (grant No. MOST 106-232-B-040-022-MY3, 105-2320-B-040-022, and 104-2320-B-040-006). The authors would like to thank the Chung Shan Medical University and Ditmanson Medical Foundation Chia-Yi Christian Hospital of the Republic of China, Taiwan, for financially supporting this research under Grant No. CSMU-CYCH-108-01. This manuscript was edited by Wallace Academic Editing.

Conflicts of Interest: The authors declare no conflict of interest.

\section{References}

1. Panpisut, P.; Khan, M.A.; Main, K.; Arshad, M.; Xia, W.; Petridis, H.; Young, A.M. Polymerization kinetics stability; volumetric changes; apatite precipitation; strontium release and fatigue of novel bone composites for vertebroplasty. PLoS ONE 2019, 14, e0207965. [CrossRef] [PubMed]

2. Moszner, N.; Fischer, U.K.; Angermann, J.; Rheinberger, V. A partially aromatic urethane dimethacrylate as a new substitute for Bis-GMA in restorative composites. Dent. Mater. 2008, 24, 694-699. [CrossRef]

3. Schulz, S.D.; Laquai, T.; Kümmerer, K.; Bolek, R.; Mersch-Sundermann, V.; Polydorou, O. Elution of Monomers from Provisional Composite Materials. Int. J. Polym. Sci. 2015, 2015, 617407. [CrossRef]

4. Silva, G.A.; Lanza, L.D.; Lopes-Junior, N.; Moreira, A.; Alves, J.B. Direct pulp capping with a dentin bonding system in human teeth: A clinical and histological evaluation. Oper. Dent. 2006, 31, 297-307. [CrossRef] [PubMed]

5. Wisniewska-Jarosinska, M.; Poplawski, T.; Chojnacki, C.J.; Pawlowska, E.; Krupa, R.; Szczepanska, J.; Blasiak, J. Independent and combined cytotoxicity and genotoxicity of triethylene glycol dimethacrylate and urethane dimethacrylate. Mol Biol Rep. 2011, 38, 4603-4611. [CrossRef] [PubMed]

6. Schneider, T.R.; Hakami-Tafreshi, R.; Tomasino-Perez, A.; Tayebi, L.; Lobner, D. Effects of dental composite resin monomers on dental pulp cells. Dent. Mater. J. 2019, 38, 579-583. [CrossRef]

7. Chang, H.H.; Chang, M.C.; Wang, H.H.; Huang, G.F.; Lee, Y.L.; Wang, Y.L.; Chan, C.P.; Yeung, S.Y.; Tseng, S.K.; Jeng, J.H. Urethane dimethacrylate induces cytotoxicity and regulates cyclooxygenase-2; hemeoxygenase and carboxylesterase expression in human dental pulp cells. Acta Biomater. 2014, 10, 722-731. [CrossRef]

8. Oishi, Y.; Manabe, I. Macrophages in inflammation; repair and regeneration. Int. Immunol. 2018, 30, 511-528. [CrossRef]

9. Howait, M.; Albassam, A.; Yamada, C.; Sasaki, H.; Bahammam, L.; Azuma, M.M.; Cintra, L.T.A.; Satoskar, A.R.; Yamada, S.; White, R.; et al. Elevated Expression of Macrophage Migration Inhibitory Factor Promotes Inflammatory Bone Resorption Induced in a Mouse Model of Periradicular Periodontitis. J. Immunol. 2019, 202, 2035-2043. [CrossRef]

10. Tsai, P.K.; Wu, S.W.; Chiang, C.Y.; Lee, M.W.; Chen, H.Y.; Chen, W.Y.; Chen, C.J.; Yang, S.F.; Yeh, C.B.; Kuan, Y.H. Evaluation of cytotoxicity; apoptosis; and genotoxicity induced by indium chloride in macrophages through mitochondrial dysfunction and reactive oxygen species generation. Ecotoxicol. Environ. Saf. 2020, 15, 110348. [CrossRef]

11. Liu, C.W.; Lin, H.W.; Yang, D.J.; Chen, S.Y.; Tseng, J.K.; Chang, T.J.; Chang, Y.Y. Luteolin inhibits viral-induced inflammatory response in RAW264.7 cells via suppression of STAT1/3 dependent NF- $\mathrm{kB}$ and activation of HO-1. Free Radic. Biol. Med. 2016, 95, 180-189. [CrossRef] [PubMed]

12. Huang, F.M.; Chang, Y.C.; Lee, S.S.; Ho, Y.C.; Yang, M.L.; Lin, H.W.; Kuan, Y.H. Bisphenol A exhibits cytotoxic or genotoxic potential via oxidative stress-associated mitochondrial apoptotic pathway in murine macrophages. Food Chem. Toxicol. 2018, 122, 215-224. [CrossRef] [PubMed]

13. Van Landuyt, K.L.; Nawrot, T.; Geebelen, B.; De Munck, J.; Snauwaert, J.; Yoshihara, K.; Scheers, H.; Godderis, L.; Hoet, P.; Van Meerbeek, B. How much do resin-based dental materials release? A meta-analytical approach. Dent. Mater. 2011, 27, 723-747. [CrossRef] 
14. Huang, F.M.; Kuan, Y.H.; Lee, S.S.; Chang, Y.C. Cytotoxicity and genotoxicity of Triethyleneglycol-Dimethacrylate in macrophages Involved in DNA damage and caspases activation. Environ. Toxicol. 2015, 30, 581-588. [CrossRef] [PubMed]

15. Löfroth, M.; Ghasemimehr, M.; Falk, A.; Vult von Steyern, P. Bisphenol A in dental materials - existence, leakage and biological effects. Heliyon. 2019, 5, e01711. [CrossRef] [PubMed]

16. Leung, D.; Spratt, D.A.; Pratten, J.; Gulabivala, K.; Mordan, N.J.; Young, A.M. Chlorhexidine-releasing methacrylate dental composite materials. Biomaterials. 2005, 26, 7145-7153. [CrossRef]

17. Huang, F.M.; Chang, Y.C.; Lee, S.S.; Yeh, C.H.; Lee, K.G.; Huang, Y.C.; Chen, C.J.; Chen, W.Y.; Pan, P.H.; Kuan, Y.H. BisGMA-induced cytotoxicity and genotoxicity in macrophages are attenuated by wogonin via reduction of intrinsic caspase pathway activation. Environ. Toxicol. 2016, 31, 176-184. [CrossRef]

18. Reichl, F.X.; Esters, M.; Simon, S.; Seiss, M.; Kehe, K.; Kleinsasser, N.; Folwaczny, M.; Glas, J.; Hickel, R. Cell death effects of resin-based dental material compounds and mercurials in human gingival fibroblasts. Arch. Toxicol. 2006, 80, 370-377. [CrossRef]

19. Poplawski, T.; Loba, K.; Pawlowska, E.; Szczepanska, J.; Blasiak, J. Genotoxicity of urethane dimethacrylate; a tooth restoration component. Toxicol. In Vitro. 2010, 24, 854-862. [CrossRef]

20. Neves, S.O.; Magalhães, L.M.D.; Corrêa, J.D.; Dutra, W.O.; Gollob, K.J.; Silva, T.A.; Horta, M.C.R.; Souza, P.E.A. Composite-derived monomers affect cell viability and cytokine expression in human leukocytes stimulated with Porphyromonas gingivalis. J. Appl. Oral. Sci. 2019, 27, e20180529. [CrossRef]

21. D'Arcy, M.S. Cell death: A review of the major forms of apoptosis; necrosis and autophagy. Cell Biol. Int. 2019, 43, 582-592. [CrossRef] [PubMed]

22. Tseng, C.Y.; Wang, J.S.; Chao, M.W. Causation by Diesel Exhaust Particles of Endothelial Dysfunctions in Cytotoxicity, Pro-inflammation, Permeability, and Apoptosis Induced by ROS Generation. Cardiovasc. Toxicol. 2017, 17, 384-392. [CrossRef] [PubMed]

23. Gallorini, M.; Cataldi, A.; di Giacomo, V. HEMA-induced cytotoxicity: Oxidative stress, genotoxicity and apoptosis. Int. Endod. J. 2014, 47, 813-818. [CrossRef] [PubMed]

24. Shalini, S.; Dorstyn, L.; Dawar, S.; Kumar, S. Old; new and emerging functions of caspases. Cell Death Differ. 2015, 22, 526-539. [CrossRef]

25. Voss, A.K.; Strasser, A. The essentials of developmental apoptosis. F1000Res. 2020, 9, F1000. [CrossRef] [PubMed]

26. Connolly, P.; Garcia-Carpio, I.; Villunger, A. Cell-Cycle Cross Talk with Caspases and Their Substrates. Cold Spring Harb. Perspect. Biol. 2020, 12, a036475. [CrossRef]

27. Vakifahmetoglu-Norberg, H.; Ouchida, A.T.; Norberg, E. The role of mitochondria in metabolism and cell death. Biochem. Biophys. Res. Commun. 2017, 482, 426-431. [CrossRef]

28. Spinelli, J.B.; Haigis, M.C. The multifaceted contributions of mitochondria to cellular metabolism. Nat. Cell Biol. 2018, 20, 745-754. [CrossRef]

29. Kausar, S.; Wang, F.; Cui, H. The Role of Mitochondria in Reactive Oxygen Species Generation and Its Implications for Neurodegenerative Diseases. Cells 2018, 7, 274. [CrossRef]

30. Chang, H.H.; Chang, M.C.; Lin, L.D.; Lee, J.J.; Wang, T.M.; Huang, C.H.; Yang, T.T.; Lin, H.J.; Jeng, J.H. The mechanisms of cytotoxicity of urethane dimethacrylate to Chinese hamster ovary cells. Biomaterials 2010, 31, 6917-6925. [CrossRef]

(C) 2020 by the authors. Licensee MDPI, Basel, Switzerland. This article is an open access article distributed under the terms and conditions of the Creative Commons Attribution (CC BY) license (http://creativecommons.org/licenses/by/4.0/). 